RESEARCH ARTICLE

\title{
Analysis on the Problems Existing in the Exploration of Geological and Mineral Resources and Their Solutions
}

\author{
Cong Zhang
}

Qingdao Geotechnical Engineering Co., Ltd., Qingdao, Shandongg, 266072, China

Abstract: The continuous development of science and technology has provided new methods for geological survey technology, and more and more new technologies have been applied to surveys to achieve an accurate grasp of geological conditions. The development of mineral resources is closely related to the development of the country, so it is very necessary to do a good job in the development and analysis of mineral resources. The current status of mineral resources exploration determines the progress of China's future mineral development work, and is also a reference for the future direction of China's energy development. The paper analyzes the main problems existing in the exploration of China's geological and mineral resources at this stage, and proposes corresponding solutions.

Keywords: Geological prospecting; Mineral resources; Problems; Solutions

Citation: Cong Zhang, 2019. Analysis on the Problems Existing in the Exploration of Geological and Mineral Resources and Their Solutions. International Journal of Geology, 4(1): 9-12. http://doi.org/10.26789/IJG.2019.01.003

Copyright: Analysis on the Problems Existing in the Exploration of Geological and Mineral Resources and Their Solutions. (C) 2019 Cong Zhang. This is an Open Access article published by Urban Development Scientific Publishing Company. It is distributed under the terms of the Creative Commons Attribution-Noncommercial 4.0 International License, permitting all non-commercial use, distribution, and reproduction in any medium, provided the original work is properly cited and acknowledged.

\section{The Application of Remote Sensing Technology in the Field of Geological Exploration in China at Present}

When using remote sensing technology to carry out geological exploration, it is only possible to apply images to a certain extent to present the geological conditions of specific areas to people's eyes. In the process of practical application of remote sensing technology, the main research is the multi-band images of the earth's surface, and this influence is taken vertically from top to bottom. In addition, the impact obtained on the basis of this shooting method must be based on experts' field investigation in the field, and then laboratory treatment in the experiment, so that accurate geological information can be obtained, and relevant data cannot be directly obtained from the impact.

When remote sensing technology is applied in the field of geological exploration, it should make the best of its strengths and avoid its weaknesses, so as to give full play to its various performances, and then make certain contributions to the development of China's geological exploration industry.

\section{Technical Principles to be Followed in China's Geological and Mineral Exploration}

\subsection{Gradually Expand in Previous Fields}

At present, the starting point of China's geological and mineral exploration work should be reversed, and the starting point should be gradually placed on various types of basic resources and complex geological conditions within China. The importance of minerals and mining areas should be distinguished. On the basis of environmental factors and engineering distribution characteristics, aiming at key mining areas and minerals, in order to improve the accuracy of China's geological and mineral resources exploration work to a certain extent, relevant work in the field of geological exploration should have a certain emphasis. On the basis of taking the actual situation of mineral resources within China as the basis, it gradually expanded in the field of geological and mineral resources exploration in the past ${ }^{[1]}$.

Under the present Chinese social background, we should constantly expand in the past geological exploration field according to the objective requirements put forward in the process of advancing the social and economic 
development, meet the actual needs put forward by relevant people in various fields, and integrate with advanced technical measures, so as to make efforts to improve the level of China's geological exploration work to a certain extent.

\subsection{Scientific and Rational Application of Various Technical Measures}

With China's entry into the era of knowledge economy, the speed of development and application of various sciences and technologies has naturally been improved to a certain extent. Under this background, advanced technical measures should naturally be applied in the field of geological exploration in China, which will gradually make the exploration of geological resources evolve towards modernization and at the same time lay a solid foundation for the smooth development of China's multi-field geological exploration work ${ }^{[2]}$. In the process of the transformation of geological exploration technology towards modernization, it is necessary to implement the principle of prospering the land through science and technology. On the basis of the organic integration of the previous exploration technology and the technical measures with a relatively high degree of modernization, we strive to achieve the goal of modernization in the field of geological exploration technology in China.

In view of China's special areas, we should treat them with certain particularity. On the basis of relevant analysis at all levels, we should gradually give full play to the performance of advanced technical measures, and make the regional advantages evolve towards scientific and technological advantages. Only when the gradually developed science and technology and geological and mineral resources are organically integrated in the process of practical work, and the scientific concept of development is implemented, can China's geological exploration industry change towards the direction of sustainable development.

\section{Remote Sensing Technology in Various Fields of Geological Exploration in China}

The geological composition is applied in the field of obtaining structural information. Endogenous mineral resources are often located on abnormal or marginal positions of geological structure, and mineral resources are mainly distributed in places where different positions of plate structure combine with each other. These geological information can be obtained by using remote sensing technology. Observing the spatial information obtained by aerial photography of remote sensors can clearly check the deposits in various plate structure positions. When the geological landmark information is extracted based on the application of remote sensing technology to a certain extent, it is usually selected from the linear and zonal influences that may include deposits. At the same time, when obtaining the information of geological plate structure, it is necessary to focus on the information in the important ore-controlling structural positions such as faults and nappes.

When scanning geological information on the basis of applying electromagnetic and spectral technology to a certain extent, because it will be affected by external factors and internal factors, it is difficult for people to clearly present some specific information of geological texture and geological linear shape in the image. In view of the vague part contained in this geological structure information, it can be applied to expert annotation and man-machine communication, so as to form a general understanding of geological structure information at key positions at will. When the geological structure information is extracted, the remote sensing geological exploration technology can extract the hidden information contained in the geological structure based on the application of data forms such as surface characteristics and geomorphological characteristics.

The cost of surveying and mapping satellite imaging technology is relatively high in the process of practical application. However, under the background of the rapid development of various science and technology, it not only reduces the cost of practical application, but also improves the imaging ability, which promotes the scale of remote sensing image data to show a trend of gradual increase. However, due to the influence of the extremely priority transmission channel capacity in the process of practical application, it is necessary to carry out data compression processing. The evaluation object of remote sensing compression technology is the impact after compression, and the evaluation content includes the contents above the geometric quality, imaging quality and subjective perception ability, so the results obtained from quality evaluation should be compressed, which can provide extremely important theoretical support during the compilation of compression ratio index of surveying and mapping satellites ${ }^{[3]}$.

In a word, mineral resources, as a kind of resources with a very limited total amount, have been widely concerned by people in all fields of society since the emergence of energy shortage. Especially, on the basis of the improvement of mineral exploration technology and the gradual improvement of mineral demand, it is even more important to find effective mineral exploration measures. Remote sensing technology occupies an important position in the field of geological exploration in China, and 
has been widely used.

Mineral resources occupy an extremely important position in the process of advancing China's national economic development. However, at present, the utilization rate of mineral resources within China's scope has not been effectively controlled, and it is difficult to form effective supervision and management of various mineral resources in the process of developing mineral resources, so it is necessary to devote ourselves to the study of geological exploration technology ${ }^{[4]}$.

\section{Problems in China's Geological and Mineral Resources Exploration}

\subsection{The Lag of Mineral Resources Exploration}

The exploration speed and intensity of China's mineral resources have been relatively lagging behind, which cannot meet the demand of mineral resources produced by Chinese society at present. The exploration of mineral resources always has great risks, and the success rate of exploration has always been very low. The process from regional mineral survey and evaluation to detailed resource survey is full of hardships and difficulties. Even though the preliminary survey is relatively smooth, it will take at least 10 years from resource survey to mine development and construction. Because of the special work of mineral resources exploration, there must be relatively sufficient risk investment, and continuous resource exploration is needed ${ }^{[5]}$.

However, most of the development funds in China's mineral resources exploration are seriously insufficient, the sources of social funds and foreign capital are not smooth, and the mineral exploration can not get strong financial guarantee, which makes all the work slow.

\subsection{Imbalance between Supply and Demand of Mineral Resources}

At present, the imbalance between supply and demand of mineral resources is a prominent problem in the protection of mineral resources. Although China is a big country with abundant mineral resources, its per capita resource holdings are at a low level in the world. From the structure of mineral resources reserves, China has large reserves of pillar mineral resources such as coal, iron, aluminum, zinc and steel, but the per capita holdings are relatively small. In addition, there is a serious imbalance between the supply and demand of mineral resources such as potassium salt and diamond.

\subsection{Unreasonable Distribution of Mineral Resources}

From the perspective of the distribution of China's mineral resources, it is common for China's mineral resources to have a small number of large mines and a large number of small mines, which shows that the distribution of China's mineral resources is unreasonable.

Although there are a large number of mineral resources in China, there are few large-scale deposits, and most of them are relatively small in scale. Although there are a large number of mineral resources developed, the amount of development is not as good as that of a large-scale international deposit. In addition, the scale of China's mineral enterprises is relatively small, and the development efforts are also small, so the mining volume is relatively low, and the problems of waste of resources and environmental pollution are also emerging one after another.

\subsection{Low Utilization Rate of Comprehensive Research}

Most of China's mineral resources are often accompanied by a large amount of coexisting minerals, but China's utilization of associated mineral resources is low, resulting in serious waste of mineral resources, which is quite different from that of western developed countries. At the same time, China started late in international resource exploration, and the exploration efforts are not enough. At present, about $90 \%$ of China's mineral resources are imported internationally, and the comprehensive utilization of China's mineral resources is very low.

\section{Measures to Improve the Present Situation of China's Mineral Resources Exploration and Development}

\subsection{Promote High Technology and Reform Exploration and Development Technology}

In the eastern part of China, the exploitation of oil has not only been limited to the current region, but has focused on the sea area. Moreover, many metal minerals have shifted from the traditional search for mines to exploration in deeper areas. This kind of exploration requires high technology, which requires not only comprehensive knowledge but also advanced technology to ensure the combination of exploration and development.

In China's resource-rich western region, coal, iron, copper and other mineral resources have been gradually explored and developed by people in recent years, but the development degree is relatively low. 
Therefore, both developed areas in the east and relatively backward areas in the central and western regions must popularize high and new technology, innovate exploration and development technology, improve the overall level of mineral exploration and development, and focus on exploration and development, so as to achieve allround improvement in technical level ${ }^{[6]}$.

\subsection{Establish and Improve the Supervision System of Mineral Resources}

In order to ensure the orderly and scientific development of China's mineral resources, it is necessary to establish a corresponding mineral resources supervision system. Firstly, according to the characteristics of China's social economy and market development at present, the national standards and systems for mineral resources development are unified, and the corresponding macro-control and management are carried out for resource exploration and development. Secondly, we should vigorously reform the multi-level management of mineral resources of regional governments, improve the efficiency of resource development management, simplify the examination and approval process of resource development, and prevent the centralization of examination and approval power. Finally, we should strengthen the management of government management departments at all levels, and set up a special resource exploration management supervision team to supervise mineral resources development professionally and scientifically.

Besides the traditional government supervision from top to bottom, the mineral resources supervision system should also include the supervision of the market itself. The market should exert its own regulating ability, strictly control the industry access, and supervise and report those that do not meet the industry access standards through industry associations.

\subsection{To Speed up the Way of Information Dissem- ination}

With the continuous development of computer technology and Internet technology, information construction has been continuously carried out in geological and mineral resources exploration, and it has been widely used. In the future exploration of mineral resources, it is necessary to constantly update and develop new science and technology, and vigorously popularize and apply the new technology, so as to improve the efficiency of resource exploration.

For example, advanced artificial intelligence technology, parallel distributed processing technology, multi-media workstations and cloud storage technology can be used to continuously strengthen and promote the popularization and application of information technology in geological resource exploration ${ }^{[7]}$. In geological exploration, remote control is realized by transmitting wireless network data through satellites, thus realizing cross-regional monitoring of geological resources exploration. In the process of resource exploration, it is also necessary to improve the automatic operation level and operation precision of detection instruments, so as to provide the required exploration data and data timely and accurately in the field exploration.

\subsection{Intensify Scientific and Technological Innovation}

Geological mineral exploration is a very dangerous job. In the actual working process, due to outdated equipment and lack of advanced science and technology, the predictability of accidents and disasters is poor. Therefore, in order to ensure the efficiency of China's geological and mineral exploration and the safety of exploration workers, it is necessary to intensify scientific and technological innovation, introduce advanced equipment and increase the investment of funds to provide safety guarantee for China's qualified mineral exploration, thus improving the efficiency of China's geological and mineral exploration and providing more energy supply for China's economic development.

In the exploration of geological and mineral resources, it is necessary to constantly improve and perfect the existing problems in resource exploration, and vigorously apply new science and technology, so as to save manpower and material resources and improve the efficiency of resource exploration. In addition, we should pay attention to the protection of regional environment in resource exploration, so as to ensure the smooth development of mineral resources and protect the surrounding environment from being destroyed, so as to realize the coordination and unity of China's resource development and environmental protection.

\section{References}

[1] Fan Hongming. Research on the Theory and Technical Methods of Mineral Geological Exploration [J]. Engineering Technology (Citation Edition), 2016:00274-00274.

[2] Wang Quanming, Ye Tianzhu, Wang Baoliang, et al. Characteristics of major metal mineral exploration in China and its enlightenment to current exploration [J]. Geology and Exploration, 2005:18-21. 